\title{
Connection between the decadal variability in the Southern Ocean circulation and the Southern Annular Mode
}

\author{
Xiao-Yi Yang, ${ }^{1}$ Dongxiao Wang, ${ }^{1}$ Jia Wang, ${ }^{2,3}$ and Rui Xin Huang ${ }^{4}$ \\ Received 27 April 2007; revised 12 June 2007; accepted 19 July 2007; published 22 August 2007.
}

[1] Previous studies demonstrated the remarkable upward trend of the Southern Annular Mode (SAM) and Southern Ocean wind stress in association with anthropogenic forcing. An oceanic reanalysis data set is used to investigate the response of the circulation in the Southern Ocean to the decadal variability of SAM. Our results indicate the strengthening and the poleward shift of the northward Ekman velocity as well as the Ekman pumping rate, which led to a corresponding strengthening trend in the Deacon Cell. This strengthening, in turn, intensified the meridional density gradient and the tilting of the isopycnal surfaces. On the interannual time scale, the Antarctic Circumpolar Currents (ACC) transport exhibits a positive correlation with SAM index as seen separately in observations. However, there is no significant trend in the total transport of ACC. Possible reasons are discussed. Citation: Yang, X.-Y., D. Wang, J. Wang, and R. X. Huang (2007), Connection between the decadal variability in the Southern Ocean circulation and the Southern Annular Mode, Geophys. Res. Lett., 34, L16604, doi:10.1029/2007GL030526.

\section{Introduction}

[2] The Southern Annular Mode (SAM) has been identified as the dominant mode of atmospheric variability with a zonally-symmetric dipole structure [Thompson and Wallace, 2000]. The connection between the SAM and the atmosphere-ocean system was examined in previous studies. Results from coarse-resolution models [e.g., Hall and Visbeck, 2002; Lefebvre et al., 2004] suggested that the high-index SAM induces anomalous northward Ekman drift, upwelling (along the margins of Antarctic continent) and downwelling (near $45^{\circ} \mathrm{S}$ ). The divergent flow from the Antarctic enhances the vertical tilting of isopycnal surfaces and thus an intensification of the Antarctic Circumpolar Current (ACC) is possible. Meredith et al. [2004] presented observational evidences that interannual changes of the ACC transport are forced by SAM variability.

[3] Since the SAM shows variability over a wide range of timescale from weeks to decades, there is a well-defined decadal trend with a drift toward the high index polarity as

\footnotetext{
${ }^{1}$ Key Laboratory of Tropical Marine Environmental Dynamics (LED), South China Sea Institute of Oceanology, Chinese Academy of Sciences, Guangzhou, China.

${ }^{2}$ International Arctic Research Center, University of Alaska Fairbanks, Fairbanks, Alaska, USA.

${ }^{3}$ Now at Great Lakes Environmental Research Laboratory (GLERL), NOAA, Ann Arbor, Michigan, USA.

${ }^{4}$ Department of Physical Oceanography, Woods Hole Oceanographic Institution, Woods Hole, Massachusetts, USA.
}

Copyright 2007 by the American Geophysical Union. 0094-8276/07/2007GL030526\$05.00 reported by Thompson et al. [2000]. Some studies attributed this trend to the ozone loss [Sexton, 2001; Thompson and Solomon, 2002] or greenhouse warming [Marshall, 2003; Fyfe et al., 1999]. Huang et al. [2006] found that the wind stress and its energy input to the ACC exhibited an upward trend during recent decades. Yang et al. [2007] put forth a positive feedback mechanism and related this wind stress trend to the Antarctic ozone depletion. The oceanic response to long-term changes of SAM-related zonal wind was investigated [e.g., Oke and England, 2004] using a coarse-resolution climate model. They found that the poleward shift of westerly wind causes the increasing poleward heat transport, which may provide a feasible interpretation to the Southern Ocean warming [Gille, 2002]. Their analysis also revealed the cooling and freshening of Antarctic Intermediate Water (AAIW). As AAIW is the upper branch of global thermohaline circulation, changes in its property can relay the variability in the Southern Ocean to the global ocean through the meridional overturning circulation.

[4] Our study is focused on decadal changes of the Southern Ocean circulation and their connection with the SAM variability. The results indicate a remarkable trend in strengthening of the meridional overturning circulation (Deacon Cell), which is consistent with the high-polarity of SAM in the last two decades. Despite showing SAMrelated changes on interannual timescales, the ACC transport does not show significant changes on decadal time scales. Possible reasons for this apparent inconsistency are discussed in Section 4.

\section{Data and Methods}

[5] The Simple Ocean Data Assimilation (SODA 1.4.2) reanalysis data set is used to study the variability of largescale circulation in the Southern Ocean. This data set is produced from a general circulation ocean model based on the Parallel Ocean Program 1.3 numerics, with an average $0.25^{\circ} \times 0.4^{\circ}$ horizontal resolution (mapped onto a $0.5^{\circ} \times$ $0.5^{\circ}$ grid) and 40 vertical levels. The model is forced by the daily surface winds from ERA-40 reanalysis for the period from 1958 to 2001.

[6] The SAM index is calculated as differences between the mean SLP anomaly at six stations close to $40^{\circ} \mathrm{S}$ and six stations close to $65^{\circ} \mathrm{S}$, following Marshall [2003]. Since it is calculated directly from station data, it is not affected by changes in observational coverage (which may lead to spurious trends in the reanalysis).

[7] The zonal wind stress drives a northward Ekman velocity in the Southern Ocean $v_{e}=-\tau_{x} /\left(\rho_{0} f h_{m}\right)$, where $\tau_{x}$ is the zonal wind stress, $h_{m}$ the mixed layer depth, and $\rho_{0}$ the average sea water density, which is approximately $1027 \mathrm{~kg} / \mathrm{m}^{3}$ in the Southern Ocean. The Ekman pumping 

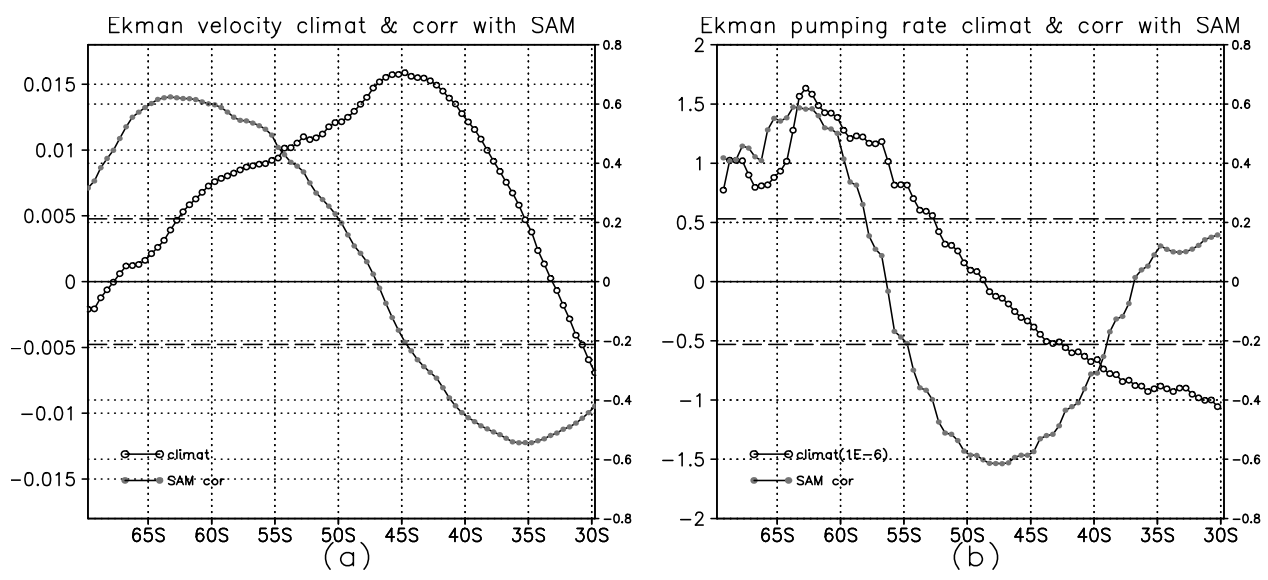

Figure 1. (a) Climatology of the zonal-mean Ekman velocity (open circle) and its correlations with the SAM index (solid circle); (b) same as Figure 1a, but for the Ekman pumping rate. The dashed lines denote the $95 \%$ significance level for the correlation coefficients.

rate is calculated as $E=-\operatorname{curl}\left(\vec{\tau} / f \rho_{0}\right)$. The Deacon Cell is identified from the meridional overturning streamfunction defined in the $y-z$ space:

$$
\psi(\theta, z)=\int_{z}^{0} \int_{\lambda_{1}}^{\lambda_{2}} v(\lambda, \theta, z) R \cos \theta d \lambda d z .
$$

\section{Results}

[8] Wind stress is one of the most important driving forces for the oceanic circulation, and its role also manifests in forms of the Ekman transport and the Ekman pumping. In the Southern Ocean, the zonal wind stress works as a direct driving force of the ACC, while the Ekman transport and its divergence are closely linked to the meridional overturning and stratification. The Ekman velocity and Ekman pumping rate climatology and their correlations with the SAM are shown in Figure 1. Climatologically, the Southern Ocean is dominated by upwelling (downwelling) south (north) of $50^{\circ} \mathrm{S}$. The upwelling, combining with the northward Ekman transport and return flows in the subsurface ocean, forms the meridional overturning circulation (Deacon Cell). During the positive phase of SAM, the circumpolar westerly strengthens and migrates poleward; thus, the northward Ekman velocity strengthens (weakens) poleward (equatorward) of $\sim 50^{\circ} \mathrm{S}$. The Ekman pumping rate exhibits a positive (negative) correlation with SAM south (north) of $\sim 55^{\circ} \mathrm{S}$, with the maximum correlation exceeds 0.60 . Therefore, the positive SAM induces the poleward shift and strengthening of northward Ekman drift as well as Ekman pumping rate, which may lead to the corresponding variability of the Deacon Cell. An empirical orthogonal function (EOF) analysis indicates that the first primary component of Deacon Cell variability represents its meridional shift, while the second component represents changes in its intensity. These two modes together can explain $76.2 \%$ of the total variance (not shown). The correlation coefficients between the two principal EOFs and the SAM are 0.65 (EOF1) and 0.38 (EOF2) respectively, both significant at the level of $95 \%$.
[9] Yang et al. [2007] demonstrated that the significant upward trends of wind stress and the SAM occur in January, following the spring Antarctic ozone depletion. Given the close connection between Southern Ocean circulation and SAM, the high polarity of SAM may lead to decadal changes of Ekman drift and Ekman pumping rate as shown in Figure 2. In the last two decades, the trends of northward Ekman velocity and Ekman pumping rate displayed dipole patterns in January. This means the strengthening of upwelling (downwelling) and acceleration (deceleration) of Ekman drift to the south (north) of $55^{\circ} \mathrm{S}$. The other significant trends occur in April-May, corresponding to the second maximum of wind stress trends [Yang et al., 2007, Figure 2].

[10] To explicitly exhibit the variability of the Deacon Cell, we searched the annual-mean maxima of meridional overturning streamfunction, and took the normalized time series as the Deacon Cell intensity index (DCI), as shown in Figure 3a. Also plotted is the normalized $60^{\circ}-45^{\circ} \mathrm{S}$ zonal wind stress. These two time series manifest a close similarity, with the correlation exceeding 0.90 . The correlation between DCI and SAM index (Figure 3c) is 0.70, indicating that the variability of Deacon Cell is strongly influenced by the SAM-related wind-stress variability. The most notable feature of DCI variability is its dramatic upward trend since the late 1970s. The linear trend of DCI during the period of $1980-1999$ is $1.59 \times 10^{-3} /$ month, which is above the $95 \%$ significance level according to the significant test method by Santer et al. [2000]. In contrast, the linear trend prior to 1980 is $-0.56 \times 10^{-3} /$ month.

[11] According to Döös and Webb [1994], the Deacon Cell is associated with the large-scale zonal excursion of the ACC axis and the systematic changes in the depth of isopycnal surfaces, which is linked to the vertical transfer of angular momentum. Thus, the variability of the Deacon Cell may influence the baroclinic transport of the ACC through its connection with the density stratification. The correlations between $60^{\circ}-45^{\circ} \mathrm{S}$ averaged meridional/vertical density gradients and the DCI are given in Figure 4. Since the Deacon Cell is shallow it mainly regulates the stratification in the upper $1 \mathrm{~km}$. A positive correlation between the DCI and the meridional density gradient can 


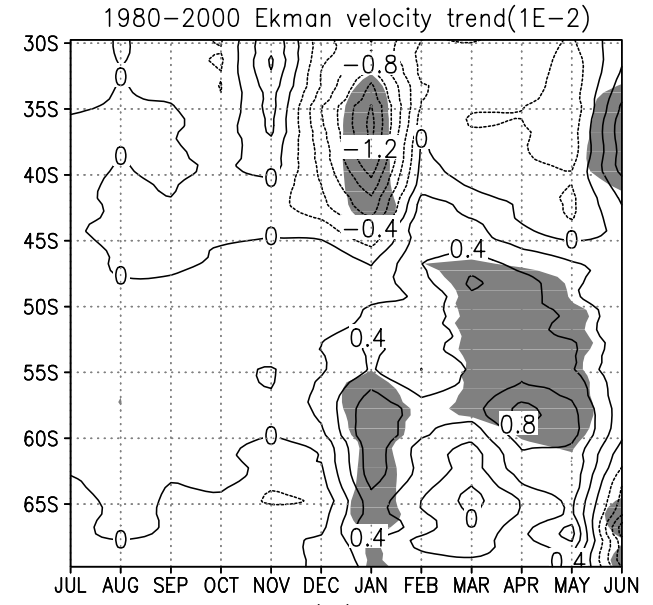

(a)
1980-2000 Ekman pumping rate trend(1E-6)

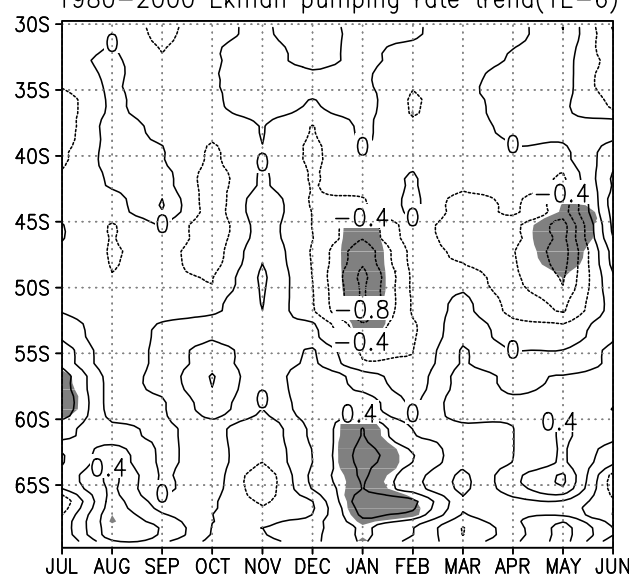

(b)

Figure 2. (a) Linear trends of the monthly zonal-mean Ekman velocity during the period of 1980-2000; (b) same as Figure 2a, but for the Ekman pumping rate. The shaded areas denote the trends above the 95\% significance level.

be identified, which is above the $95 \%$ significance level in the upper $500 \mathrm{~m}$. The vertical density gradient displays a zigzag correlation pattern with DCI, which matches the staircase structure of the Deacon Cell on isopycnal surfaces. The isopycnal slope can be calculated from $S=-\left|\nabla_{h} \rho\right| / \bar{\rho}_{z}$ (where $\nabla_{h}$ is a horizontal gradient operator). It is readily seen that the positive DCI corresponds to the increased tilting of isopycnal surfaces. The significant correlations between DCI and isopycnal slope are located at the Ekman layer (upper $50 \mathrm{~m}$ ) and at $100-300 \mathrm{~m}$ levels. On the decadal time scale, isopycnal slopes of the Southern Ocean exhibit an upward trend similar to that of the Deacon Cell (Figure 3b), which is significant during the post-1980 period.

[12] The strengthening of the Deacon Cell in response to the SAM has important implications for the variability of the ACC transport. Through the thermal wind relation, the intensification of meridional density gradient is directly linked to the enhancement of the baroclinic transport of the ACC. On the other hand, stronger tilting of isopycnal surfaces can facilitate the conversion of available potential energy of the mean flow to eddy energy. Therefore, the increased wind energy input can be used to intensify the eddy activity, instead of driving a stronger zonal current. Since the Deacon Cell dominates at the upper $500 \mathrm{~m}$ levels, we plot the annual-mean transport through Drake Passage in the upper $500 \mathrm{~m}$ against the SAM index (Figure 3c). The two time series manifest a significant positive correlation of 0.46. In spite of the remarkable interannual correlation with the SAM, the ACC transport does not show any obvious decadal variability. Although some modeling studies proclaimed the strengthening trend of the ACC transport in response to changes of wind stress, in-situ measurements (either Inter-disciplinary Southern Ocean Studies (ISOS) or the World Ocean Circulation Experiment (WOCE) data) revealed no significant decadal trend of the ACC transport [see Olbers et al., 2004; Cunningham et al., 2003], and this is re-confirmed by this study. Thus, on the decadal time scale, the SAM has very little impact on the ACC transport.

[13] These preliminary analyses indicate that the increased wind energy input in the ACC does not necessarily

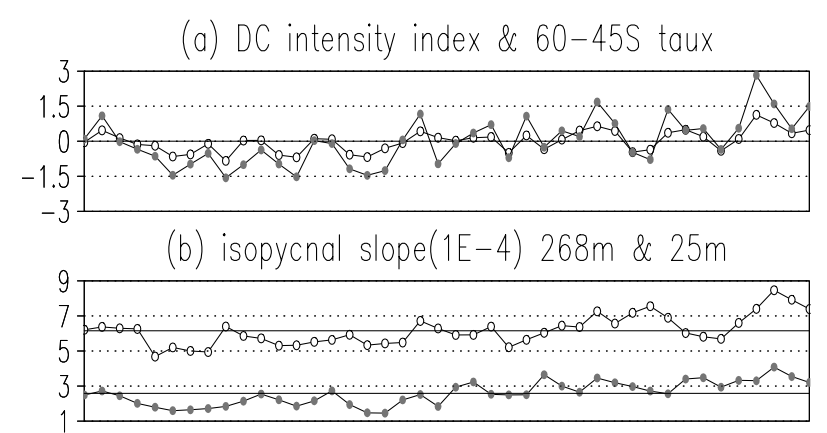

(c) SAM \& 500m ACC transport

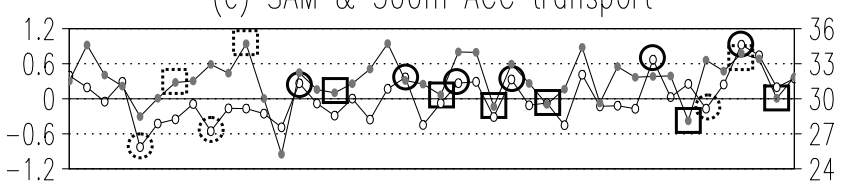

(d) normalized 500m ACC transport \& EKE

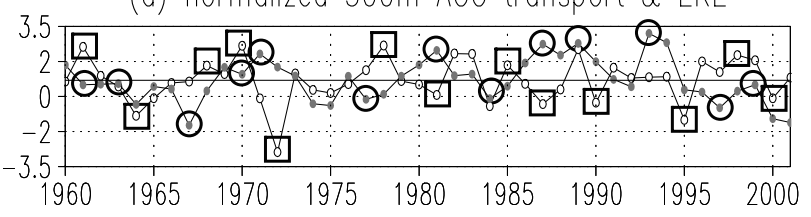

Figure 3. Time series of (a) normalized Deacon Cell intensity index (open circle) and the $60^{\circ}-45^{\circ} \mathrm{S}$ mean zonal wind stress (solid circle); (b) the $60^{\circ}-45^{\circ} \mathrm{S}$ mean isopycnal slope at the $268 \mathrm{~m}$ level (open circle) and $25 \mathrm{~m}$ level (solid circle); (c) the SAM index (open circle) and upper $500 \mathrm{~m}$ Drake Passage transport (solid circle). The solid signs represent the SAM peaks (ellipses) followed by the minima of the ACC transport (squares); the dashed signs represent the SAM minima (ellipses) followed by maxima of the ACC transport (squares) with a 2-year time lag; (d) normalized upper $500 \mathrm{~m}$ ACC transport (open circle) and the eddy kinetic energy (EKE, solid circle). The ACC transport maxima/minima (squares) correspond to the EKE minima/ maxima (ellipses) with zero lag or one-year lag. See text for details. 


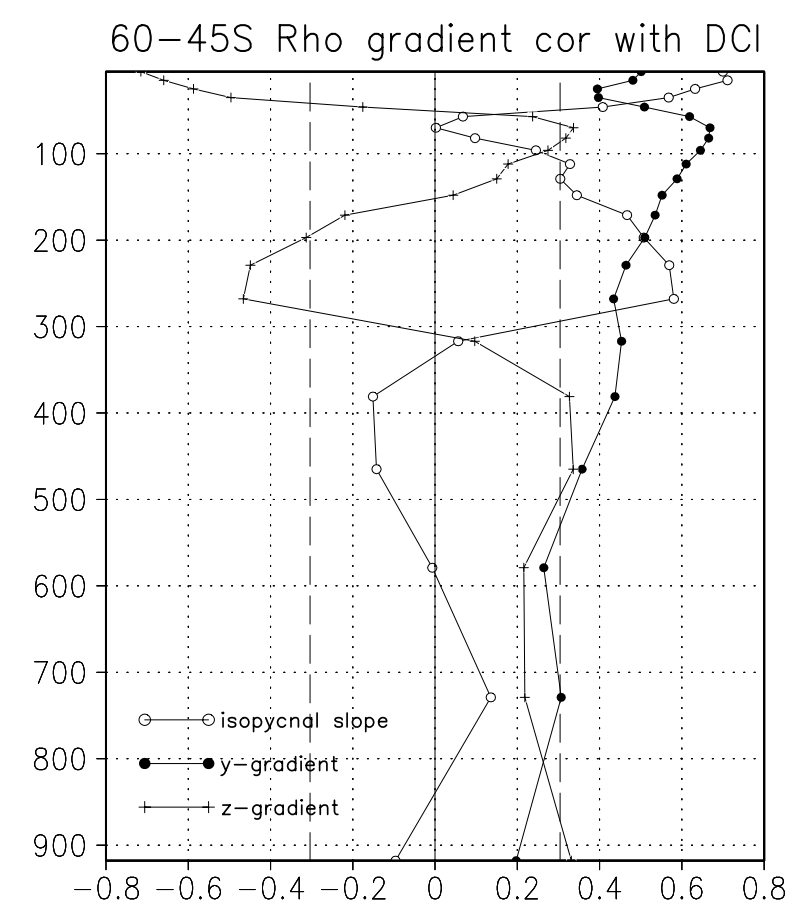

Figure 4. Correlation coefficients between the Deacon Cell intensity index and the $60^{\circ}-45^{\circ} \mathrm{S}$ mean isopycnal slope (open circle), the meridional density gradient (solid circle) and vertical density gradient (cross). The dashed lines denote the $95 \%$ significance level for the correlation coefficients.

imply a direct enhancement of ACC transport on a longterm period. Instead, this increased input of mechanical energy can be dissipated through certain dynamical adjustment processes, which helps to counteract the decadal strengthening SAM-related wind stress and maintain the steadiness of the ACC transport in the decadal time scale.

\section{Conclusions and Discussion}

[14] Our analyses reveal that during the positive phase of SAM, both the northward Ekman velocity and the Ekman pumping rate strengthen and shift poleward. The resulting changes in the Deacon Cell affect the stratification and isopycnal slope, which in turn enhance the baroclinic transport of the ACC. During the last two decades, the upward trends of SAM strengthened the Deacon Cell; in contrast, the decadal increase of SAM does not seem to drive an upward trend in ACC transport, despite the dependence of the ACC transport on SAM on interannual timescale.

[15] Some previous studies predicted the acceleration of the ACC in response to the SAM high polarity [Gnanadesikan and Hallberg, 2000]. However, our analyses showed no signal of decadal variability of the ACC transport. To explore this inconsistency, we investigate more closely the time series of SAM index and ACC transport (Figure 3c). In addition to the positive correlation between the SAM and ACC transport at zero lag, a loose relationship exists between ACC transport and the SAM at a 2-year lag: the SAM peaks (solid ellipses) are sometimes followed by the minima of the ACC transport (solid squares) with a lag of
2 years. Although the linear 2-year lag correlation of the two time series is only marginal significant $(-0.21$ for 42 years), the composite analyses show that SAM high index corresponds to the increase of the ACC transport to about $2.4 \mathrm{~Sv}$ at 0 -year lag (significant at $95 \%$ level t-test), and the decrease of the ACC transport to about $-1.5 \mathrm{~Sv}$ at 2 -year lag (significant at $80 \%$ level t-test; figures not shown).

[16] The above-mentioned lag response of the ACC transport to SAM may involve the eddy-related baroclinic dissipation process. Hallberg and Gnanadesikan [2001] suggested that the ACC transport is linearly related to the wind stress for the case with weak wind forcing or strong diabatic forcing. However, for strong wind forcing, the eddy flux intensifies as wind stress increases; while the ACC transport remains relatively unchanged. Recently, Meredith and Hogg [2006] uncovered the 2-3 year lag response of eddy kinetic energy to the zonal wind stress, and this may be due to the baroclinic adjustment process transferring wind energy to the deep ocean. We further construct the normalized time series of eddy kinetic energy (solid circle) in the ACC region versus that of ACC transport (open circle) (Figure 3d). The linear correlation is insignificant at zero lag and marginal significant $(-0.23$ at $85 \%$ significance level) at 1 year lag (ACC transport following EKE). This may result from the nonlinear connection of the two variables or the data quality problem. Nevertheless, the case study again suggests certain linkage as we highlighted with ellipses and square signs. There are some years that the ACC transport maxima/minima (squares) correspond to the EKE minima/maxima (ellipses) at zero lag or one-year lag. It is speculated that strengthening of eddy activity may slowly dissipate the mean flow energy, thus decreasing the ACC transport with a certain lag time. Therefore, the eddymean flow interaction and its effect on ACC momentum balance may account for the steadiness of ACC transport on decadal time scale, which deserve further investigations using an eddy-resolving model. It is worth noting that there is an upward trend of EKE from late-1970s to mid-1990s (Figure 3d). But after that, EKE decreases remarkably. The dynamic nature of this decline remains unclear at this time.

[17] Finally, note that SODA 1.4.2 is a reanalysis product. It has its limitations and uncertainties for the study of the decadal variability, particularly in the data-sparse Southern Ocean. In essence, dynamical phenomena on the decadal timescales considered here are primarily obtained from the underlying dynamics of the model, which is only poorly constrained by observations in the Southern Ocean (especially in earlier periods). Carton and Giese (SODA: A reanalysis of ocean climate, submitted to Monthly Weather Review, 2007) reported that the SODA 1.4.2 shows eddy kinetic energy higher than previous versions and the decadal variability of upper ocean $(0-$ $700 \mathrm{~m}$ ) heat content more closely resembles the observation-based variability. Thus, our analysis is confined to the upper Southern Ocean. Nevertheless the full-depth integration of ACC transport (not shown) exhibits no signal of decadal variability either. Moreover, results from a highresolution $\left(1 / 4^{\circ} \times 1 / 6^{\circ}\right)$ atmosphere-ice-ocean climate model [Watanabe et al., 2006] do not show upward trend during 1991-1999 (not shown). These, together with the observational evidences from Cunningham et al. [2003], 
may partly support our statistical results, though the mechanism responsible for the steadiness of the ACC transport remains to be explored.

[18] Acknowledgments. We appreciate the anonymous reviewers for their insightful comments and suggestions. This work was supported by the Chinese Academy of Sciences (Grant KZSW2-YW-214), the Natural Science Foundation of China (Grant 40640420557) and National Basic Research Program of China (Grant 2006CB403604) for X-Y. Yang and D. Wang, and by W. Alan Clark Chair from Woods Hole Oceanographic Institution for R.X. Huang. During the course of this research, X.-Y. Yang visited J. Wang at IARC/UAF with support by the MMS/CMI awarded to J. Wang, who also thanks T. Suzuki and JAMSTEC, Japan for support in using CCSR/NIES/FRCGC GCM results.

\section{References}

Cunningham, S. A., S. G. Alderson, B. A. King, and M. A. Brandon (2003), Transport and variability of the Antarctic Circumpolar Current in Drake Passage, J. Geophys. Res., 108(C5), 8084, doi:10.1029/ $2001 \mathrm{JC} 001147$.

Döös, K., and D. J. Webb (1994), The Deacon cell and the other meridional cells of the Southern Ocean, J. Phys. Oceanogr., 24, 429-442.

Fyfe, J. C., G. J. Boer, and G. M. Flato (1999), The Arctic and Antarctic oscillations and their projected changes under global warming, Geophys. Res. Lett., 26, 1601-1604.

Gille, S. (2002), of the Southern Ocean since the 1950s, Science, 295, $1275-1277$.

Gnanadesikan, A., and R. W. Hallberg (2000), On the relationship of the Circumpolar Current to Southern Hemisphere winds in coarse-resolution ocean models, J. Phys. Oceanogr., 30, 2013-2034.

Hall, A., and M. Visbeck (2002), Synchronous variability in the Southern Hemisphere atmosphere, sea ice, and ocean resulting from the Annular Mode, J. Clim., 15, 3043-3057.

Hallberg, R., and A. Gnanadesikan (2001), An exploration of the role of transient eddies in determining the transport of a zonally reentrant current, J. Phys. Oceanogr., 31, 3312-3330.

Huang, R. X., W. Wang, and L. L. Liu (2006), Decadal variability of wind energy input to the world ocean, Deep Sea Res., Part II, 53, 31-41.

Lefebvre, W., H. Goosse, R. Timmermann, and T. Fichefet (2004), Influence of the Southern Annular Mode on the sea ice-ocean system, J. Geophys. Res., 109, C09005, doi:10.1029/2004JC002403.
Marshall, G. J. (2003), Trends in the Southern Annular Mode from observations and reanalyses, J. Clim., 16, 4134-4143.

Meredith, M. P., and A. M. Hogg (2006), Circumpolar response of Southern Ocean eddy activity to a change in the Southern Annular Mode, Geophys. Res. Lett., 33, L16608, doi:10.1029/2006GL026499.

Meredith, M. P., P. L. Woodworth, C. W. Hughes, and V. Stepanov (2004), Changes in the ocean transport through Drake Passage during the 1980s and 1990s, forced by changes in the Southern Annular Mode, Geophys. Res. Lett., 31, L21305, doi:10.1029/2004GL021169.

Oke, P. R., and M. H. England (2004), Oceanic reponse to changes in the latitude of the Southern Hemisphere subpolar westerly winds, J. Clim., $17,1040-1054$.

Olbers, D., D. Borowski, C. Völker, and J. Wolff (2004), The dynamical balance, transport and circulation of the Antarctic Circumpolar Current, Antarct. Sci., 16, 439-470.

Santer, B. D., T. M. L. Wigley, J. S. Boyle, D. J. Gaffen, J. J. Hnilo, D. Nychka, D. E. Parker, and K. E. Taylor (2000), Statistical significance of trends and trend differences in layer-average atmospheric temperature time series, J. Geophys. Res., 105, 7337-7356.

Sexton, D. M. H. (2001), The effect of stratospheric ozone depletion on the phase of the Antarctic Oscillation, Geophys. Res. Lett., 28, 3697-3700.

Thompson, D. W. J., and S. Solomon (2002), Interpretation of recent Southern Hemisphere climate change, Science, 296, 895-899.

Thompson, D. W. J., and J. M. Wallace (2000), Annular modes in the extratropical circulation. Part I: Month-to-month variability, J. Clim., $13,1000-1016$.

Thompson, D. W. J., J. M. Wallace, and G. Hegerl (2000), Annular modes in the extratropical circulation. Part II: Trends, J. Clim., 13, 1018-1036.

Watanabe, E., J. Wang, T. Sumi, and H. Hasumi (2006), Arctic Dipole and its contribution to sea ice exports from the Arctic Ocean in the last 20th century, Geophys. Res. Lett., 33, L23703, doi:10.1029/2006GL028112.

Yang, X. Y., R. X. Huang, and D. X. Wang (2007), Decadal changes of wind stress over the Southern Ocean associated with Antarctic ozone depletion, J. Clim., 20, 3395-3410.

R. X. Huang, Department of Physical Oceanography, Woods Hole Oceanographic Institution, Woods Hole, MA 02543, USA.

D. Wang and X.-Y. Yang, Key Laboratory of Tropical Marine Environmental Dynamics (LED), South China Sea Institute of Oceanology, Chinese Academy of Sciences, Guangzhou 510301, China. (dxwang@ scsio.ac.cn; yxy@scsio.ac.cn)

J. Wang, Great Lakes Environmental Research Laboratory (GLERL), NOAA, 2205 Commonwealth Blvd., Ann Arbor, MI 48105-2945, USA. 